\title{
EFFECTS OF GROUND CONDITIONS ON WHOLE-BODY VIBRATION EXPOSURE ON CARS: A CASE STUDY OF DRIVERS OF ARMORED VEHICLES
}

\author{
GUIDO ALFARO DEGAN, GIANLUCA COLTRINARI, DARIO LIPPIELLO \& MARIO PINZARI \\ Department of Engineering, University of Roma Tre, Italy
}

\begin{abstract}
The purpose of this paper is to highlight how the types of road and the vehicle characteristics influence the whole-body vibration (WBV) exposures. WBV exposure is common in occupational drivers and it can generate serious musculoskeletal injuries of the arms, shoulders, neck and lower back. Numerous studies have shown that many factors influence the dose exposure: the driver's position, style guide, vehicle speed and the driver's physical characteristics, such as body weight and height. In order to point out possible interactions between exposure to whole body vibration, vehicle characteristics and the types of road, an experimental campaign was created: firstly, a model standard car for urban use was utilized, and later, the same model vehicle was modified by the armour-plate installation for the ballistic protection. Each vehicle was driven by the same driver for a defined time on a curvilinear common urban route, along both rise and downhill directions. The assessment of the daily vibration dose was carried out in accordance with ISO 2631-1(1997) standard and expressed as the weighted frequency equivalent continuous root mean squared (RMS) acceleration over an eight-hour period. The results obtained from the experimental campaigns revealed that the WBV exposure is strongly conditioned by vehicle characteristics. In particular the installation of bulletproof armour contributed to change the car mass distribution and its total weight, modifying the professional dose. This modification generated an attenuation of frequency-weighted RMS. acceleration values all over the frequency spectrum and consequently a WBV exposure reduction. The present study encourages further study in order to understand how different factors influence exposure to WBV research.
\end{abstract}

Keywords: whole-body vibration, worker exposure, armoured vehicles.

\section{INTRODUCTION}

The human exposure to the vibrations induced by a moving vehicle was analyzed by many researchers. The injuries to the low back are considered the most significant non-lethal medical conditions affecting the operators of all types of vehicles [1]. One of the leading risk factors for the development of low back disorders is continuous exposure to whole-body vibration (WBV) [2]. For example, it is estimated that in Great Britain each week over 9 million people are exposed to the occupational WBV. Of these exposures, 374,000 exceed recommended limits with mechanical truck drivers exceeding this maximum value more than any other occupation [3]. There are numerous scientific studies that explore driver's WBV exposure levels in different job sectors [4]. Some analyze the operator's exposure during the operations on large earth moving machinery in the quarry and construction sector [5]. Others focus on the bus drivers; this worker group is one of those indicated widely as being at an increased risk for Low Back Pain (LBP) [6]. Also, farming is a particular occupation in which whole body vibration (WBV), mechanical shocks and awkward postures on the seat are present and all accepted as low back pain (LBP) risk factors for the human health [7]. In regards the police officers, they spend substantial parts of their working shift in their vehicle, either driving or performing work related tasks, increasing the risk of injury. In all aspects of police work, ranging from physical criminal restraint to automotive pursuit until arrest, the policemen are exposed to physical stressors and whole-body vibrations, which may put them at risk due to the arise of musculoskeletal pain or permanent injuries [8]. In fact, it's 
recognized that greater levels of low back pain, shoulder, hand, and wrist problems occur with increased exposure to occupational driving, both with standard patrol cars and with particular vehicles like armored cars [9]. Many studies have scrutinized occupational WBV exposure research into occupational mechanical shocks and their effects on the human body, but they are not comprehensive [10]. A dose-response relationship has been established showing that increases in the duration of WBV exposure are associated with an increased risk for injury [11]. Although it has been established that there is a relationship of exposure - response of human body between WBV and back disorders, the mechanisms that rule this phenomenon are not currently well understood. The transmissibility of the human body depends on the various biodynamic responses of the body, particularly those between the point at which the vibration enters in the body and the stitch at which it is measured [12]. Several factors are identified as being important on the WBV exposure. The type of seat can perform differently the role of attenuate vibration exposure for the driver but, in some cases, the seat can amplify the exposure [13]. The understanding of seat performance is not well quantified, also on the base of the driving style. Moreover, the WBV exposure is connected with the subject's physical characteristics like weight and height [14], driver's posture, terrain conditions and driving style. Also, the structural characteristics of the vehicle influence the exposure to WBV of the drivers, such as the armor addition on the chassis for the protection by bullets [15]. Limited research exists that quantitatively describes postural and load exposures associated with police work on the cars. For this reason, this study aims at investigating the influence of inertial characteristics of the vehicle on the worker's exposure when the structure of the chassis is changed by the addition of bulletproof armor [16]. This installation is generally realized on wheeled and tracked military terrain vehicles but it has also become more common among urban employment cars for police patrol activities.

\section{MATERIALS AND METHODS}

The aim of this paper is to investigate the influence of inertial characteristics of the vehicle on the worker's exposure when the structure of the chassis is modified by the addition of bulletproof armor. The study is comprised of two phases. The first phase of the study was designed to determine the WBV driver's exposure on a standard vehicle while the second was intended to determine the WBV exposure, for the same driver, on an identical vehicle model, modified with the bullet proof. The tests were realized on a curvilinear urban road under the same boundary conditions.

\subsection{Operators}

The driver participant was selected from a group of drivers for his anthropometric characteristics, considering him as the most representative of the police drivers. Prior to measurements, the operator completed a questionnaire to gather information on anthropometric characteristics, about his work experiences with regard to any existing musculoskeletal disorders. The answers showed that he was 1.80 meters tall, his weight was $80 \mathrm{~kg}$ and didn't have any low back gain injuries.

\subsection{Data collection procedure and test site}

WBV was measured at the operator/seat interface under the normal daily working conditions for a duration of an hour during each experimental campaign phase. The investigator was seated in the vehicle near the operator during vibration measurement, he controlled the correct device functioning and noted the start and end times of each test so that separate 
analysis could be made for each measure. The WBV exposure was measured for five cycles in each direction (rise and downhill) while the driver was driving on test track, first in rise direction and subsequently downhill. The test time was 10 minutes and the test track was 0.8 $\mathrm{km}$ length on both directions, characterized by a curvilinear shape with four curves (see Fig. 1). The speed of the vehicle was constant during the test and fixed at $50 \div 10 \mathrm{~km} / \mathrm{h}$. Each test was undertaken during the same time slot (10:00-12:00 a.m.) to ensure traffic repeatable conditions.

\subsection{Measurement of whole-body vibration}

The vibration signal was measured in accordance with the ISO 2631-1(1997) standard, using a piezoelectric tri-axial accelerometer manufactured by Spectra society. A uniaxial accelerometer PCB 393A03 was fixed on both vehicles through a permanent magnet to a special iron bar fixed under the driver's seat in order to measure the input signal. The aim was check that the vibration signal received at the seat base was repetitive for all subjects [16]. The device was set to record accelerations with a $10 \mathrm{~V}$ gain value in order to avoid overload with a sampling rate of $1250 \mathrm{~Hz}$. Table 1 reports instrument characteristics.

The device was mounted in a rubber seat pad $(20 \mathrm{~cm}$ diameter and $0.5 \mathrm{~cm}$ thick in center) and then fastened through scotch tape to the driver's seat of the vehicle (see Fig. 1). The seat pad containing the accelerometer was positioned beneath the driver's backside as outlined in the ISO 2631-1(1997) standard. The seat was aligned according to axis standard reference system for the purpose of measure the $\mathrm{x}$-axis fore-aft vibration, the $\mathrm{y}$-axis lateral vibration and the z-axis vertical vibration. The sampling frequency was $1250 \mathrm{~Hz}$ according to Shannon theorem while the frequency range was from $0.5 \mathrm{~Hz}$ to $250 \mathrm{~Hz}$. Finally, the instrument was attached to a portable programmable data acquisition unit, Sound book System, and the data obtained from the measurements were analyzed through Noise Vibration Work program.

Table 1: Characteristics of instruments.

\begin{tabular}{|c|c|c|}
\hline Model & Sensitivity & Position \\
\hline $\begin{array}{c}\text { Triaxial } \\
\text { accelerometer } \\
\text { SEN027-PCB }\end{array}$ & $\begin{array}{c}\text { X axis: } 10.52 \mathrm{mV} /\left(\mathrm{m} / \mathrm{s}^{2}\right) \\
\text { Z axis: } 10.55 \mathrm{mV} /\left(\mathrm{m} / \mathrm{s}^{2}\right)\end{array}$ & $\begin{array}{c}\text { Driving seat of the vehicle in the position } \\
\text { which corresponds to the driver's } \\
\text { sacroiliac joints (his buttocks) }\end{array}$ \\
\hline $\begin{array}{c}\text { Uni-axial } \\
\text { accelerometer } \\
\text { PCB 393A03 }\end{array}$ & Z axis: $10.55\left(\mathrm{~m} / \mathrm{s}^{2}\right)$ & $\begin{array}{c}\text { Axis sensitive in the vertical direction, } \\
\text { same direction of the } Z \text { axis of the } \\
\text { tri-axial accelerometer (vertical axis). }\end{array}$ \\
\hline
\end{tabular}
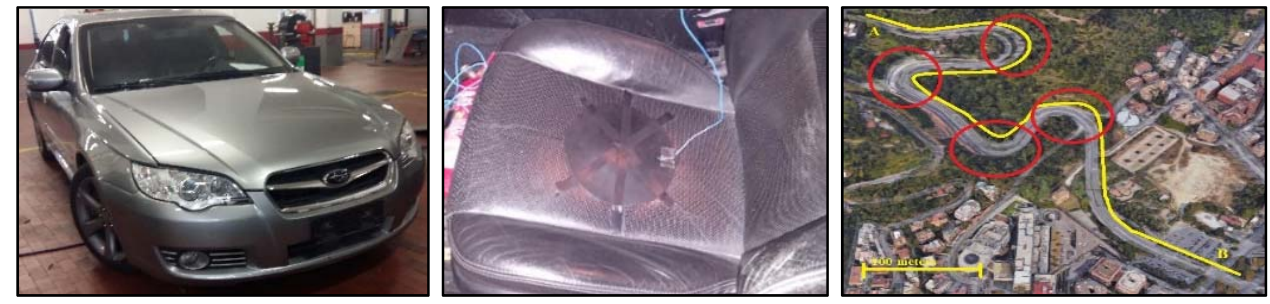

Figure 1: Armored model vehicle (left figure), transducer positioning on driver's seat (central figure) and characteristics of route (right figure - red circles indicate curves). 
Table 2: Characteristics of vehicles.

\begin{tabular}{|l|c|c|c|}
\hline Model vehicle & Year & Weight & $\mathrm{Km}$ \\
\hline Subaru legacy standard model & 2008 & 1.60 tons & $170.000 \mathrm{~km}$ \\
\hline Subaru legacy armored model & 2009 & 1.82 tons & $169.400 \mathrm{~km}$ \\
\hline
\end{tabular}

Both models had a manual transmission system with cruise control. As shown, the two models were different due to the addition of the bulletproof armor, so in terms of total weight, there was a difference of more than $200 \mathrm{~kg}$ together with a variation of mass distribution (Table 2).

\subsection{Data analysis}

All vibration data were analyzed in accordance with the ISO 2631-1(1997) standard. Data were transferred, from the Samurai software to Noise Vibration Work program in order to calculate the frequency-weighted accelerations along three orthogonal axes of the standard reference system. The determination of this parameter is necessary to compute the $A(8)$ parameter through the following expression (1):

$$
A(8)=a_{w} \sqrt{\frac{T_{e s p}}{8}} \mathrm{~m} / \mathrm{s}^{2},
$$

where:

A (8) is the daily dose expressed as $\left[\mathrm{m} / \mathrm{s}^{2}\right]$

$\mathrm{T}_{\exp }$ is the exposure time expressed as [hour]

$\mathrm{a}_{\mathrm{w}}$ is the equivalent continuous RMS acceleration also expressed as $\left[\mathrm{m} / \mathrm{s}^{2}\right]$.

The $\mathrm{A}(8)$ parameter is calculated as the highest (RMS) value of the frequencyweighted accelerations, determined on the three orthogonal axes following the expression:

$$
a_{w}=\max \left(K_{x} a_{w x}, K_{y} a_{w y}, K_{z} a_{w z}\right),
$$

where $\mathrm{a}_{\mathrm{w}, \max }$ is the maximum value among $1.4{ }_{\mathrm{aw}, \mathrm{x},}, 1.4_{\mathrm{aw}, \mathrm{y}}$ and $1{ }_{\mathrm{aw}, \mathrm{z}}$ for a seated or standing worker.

\section{RESULTS}

In the experimental campaign 2 set tests were realized and 20 complete WBV measurements were obtained for standard and armored vehicles. The following graphs show, expressed in terms of $a_{w}$, the time history (Fig. 2) and frequency spectrum (Fig. 3) along each of the three axes of the reference system standard, for standard vehicle (blue line $=\mathrm{X}$-axis, red line $=\mathrm{Y}$ axis, green line $=\mathrm{Z}$-axis).

Figs 4 and 5 (respectively) show the vibration signal of the standard vehicle and corresponding frequency spectrum.

The results of the measurements are summarized in the Table 3 . The columns of the table show the different parameters obtained from all data, divided for each vehicle and on the base of the toward. All acceleration values are expressed in terms of $\mathrm{m} / \mathrm{s}^{2}$.

In the Table 4 the difference between the two sets of data obtained on both vehicles, is highlighted through percentage values.

\section{DISCUSSION}

The data obtained in the measurement campaign point out a correlation between exposure to WBV and installation of bulletproof armor on the chassis. The first relevant consideration is 
that the measurement results show the dominant frequencies fall in the same frequency range for both vehicles $(4-12.5 \mathrm{~Hz})$, with an exception of $Z$ axis for standard vehicle $(5-16 \mathrm{~Hz})$. The second point consists that the data obtained on rise direction have less values respect to other direction on both vehicles. The third aspect is that the frequency-weighted RMS. acceleration values measured on the standard vehicle, result higher than ones of the other

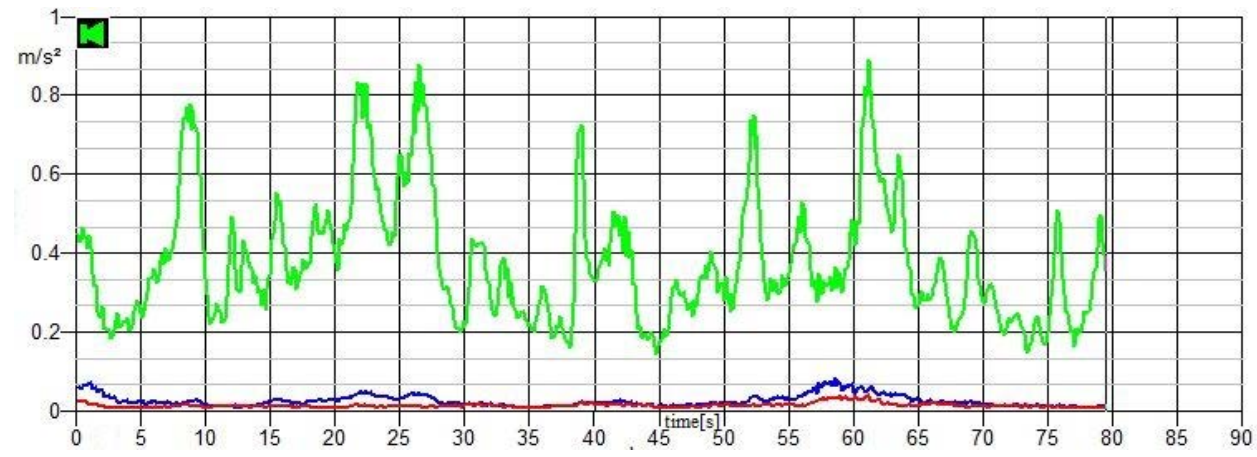

Figure 2: Signal along three axes of armored vehicle.

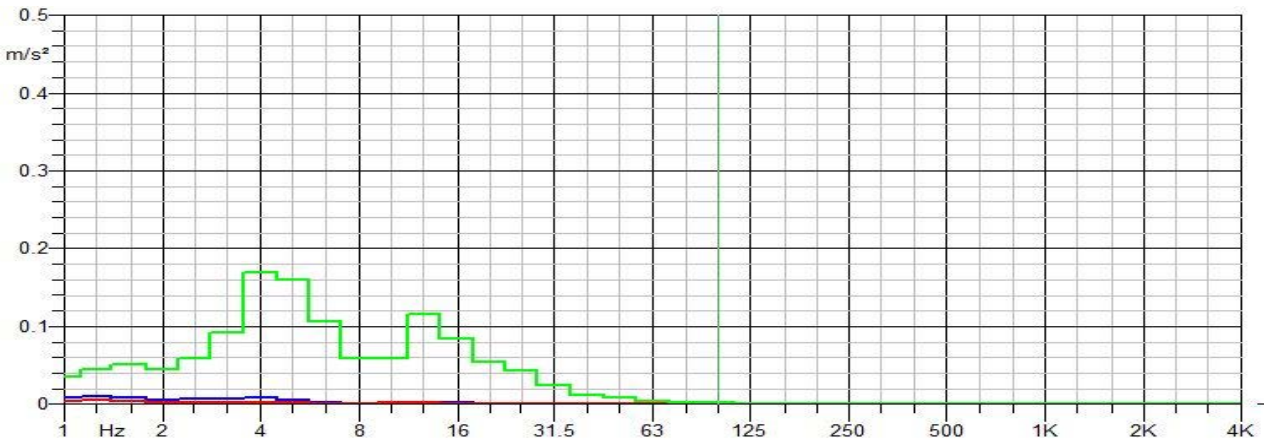

Figure 3: Frequency spectrum of armored vehicle.

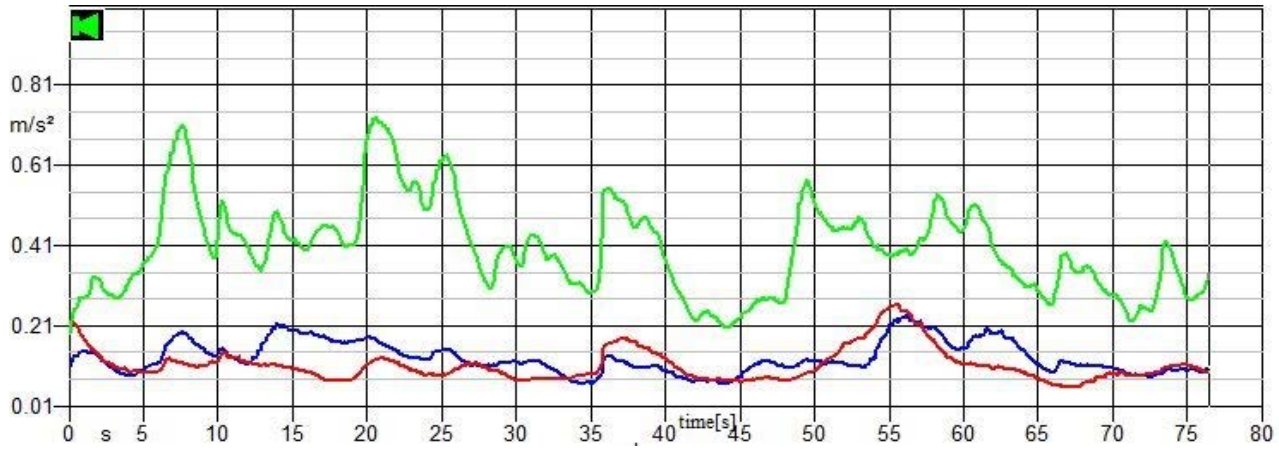

Figure 4: Time history of the signal along three axes of the standard vehicle. 


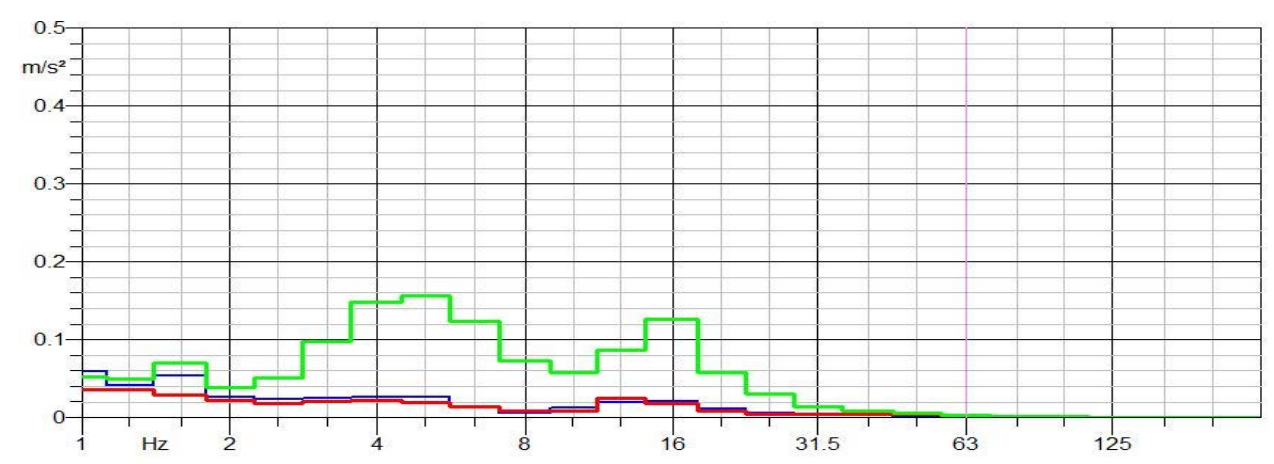

Figure 5: Frequency spectrum of the signal for the standard vehicle.

Table 3: Results of the measurement.

\begin{tabular}{|c|c|c|c|c|c|c|c|c|c|c|c|c|}
\hline $\begin{array}{c}\text { Test } \\
\text { track }\end{array}$ & $\begin{array}{c}\text { Frequency- } \\
\text { weighted RMS } \\
\text { accelerations } \\
\left(\mathrm{m} / \mathrm{s}^{2}\right)\end{array}$ & \multicolumn{2}{c|}{$\begin{array}{c}\text { Instantaneous } \\
\text { peak accelerations } \\
\left(\mathrm{m} / \mathrm{s}^{2}\right)\end{array}$} & \multicolumn{2}{c|}{$\begin{array}{c}\text { Dominant } \\
\text { frequencies }(\mathrm{Hz})\end{array}$} & $\begin{array}{c}\text { Estimated } \\
\text { daily exposure }\end{array}$ \\
\hline Toward & $\mathrm{a}_{\mathrm{wx}}$ & $\mathrm{a}_{\mathrm{wy}}$ & $\mathrm{a}_{\mathrm{wz}}$ & $\mathrm{a}_{\mathrm{wx}}$ & $\mathrm{a}_{\mathrm{wy}}$ & $\mathrm{a}_{\mathrm{wz}}$ & $\mathrm{DF}_{\mathrm{x}}$ & $\mathrm{DF}_{\mathrm{y}}$ & $\mathrm{DF}_{\mathrm{z}}$ & $\mathrm{A}(8 \mathrm{~h})$ \\
\hline \multicolumn{8}{|c|}{ Armored Vehicle } \\
\hline Rise & 0.02 & 0.01 & 0.31 & 0.03 & 0.02 & 0.79 & 4 & $\begin{array}{c}4- \\
10\end{array}$ & 4 & 0.34 \\
\hline Downhill & 0.03 & 0.01 & 0.41 & 0.08 & 0.04 & 0.88 & 3.2 & $\begin{array}{c}4- \\
10\end{array}$ & 4 & 0.41 \\
\hline & \multicolumn{8}{|c|}{ Standard Vehicle } \\
\hline Rise & 0.11 & 0.09 & 0.38 & 0.18 & 0.14 & 0.56 & $\begin{array}{c}4- \\
16\end{array}$ & $\begin{array}{c}4- \\
12.5\end{array}$ & $5-16$ & 0.38 \\
\hline Downhill & 0.14 & 0.12 & 0.42 & 0.22 & 0.29 & 0.79 & $\begin{array}{c}4- \\
16\end{array}$ & $\begin{array}{c}4- \\
12.5\end{array}$ & $5-16$ & 0.43 \\
\hline
\end{tabular}

Table 4: Comparison of vehicle model results.

\begin{tabular}{|c|c|c|c|c|}
\hline \multirow[t]{2}{*}{$\begin{array}{c}\text { Comparison vehicle } \\
\text { model }\end{array}$} & \multicolumn{3}{|c|}{$\begin{array}{l}\text { Frequency-weighted RMS accelerations } \\
\qquad\left(\mathrm{m} / \mathrm{s}^{2}\right)\end{array}$} & \multirow{2}{*}{$\begin{array}{c}\begin{array}{c}\text { Estimated daily } \\
\text { exposure }\end{array} \\
\text { A }(8 \mathrm{~h})\end{array}$} \\
\hline & $a_{w x}$ & $\mathrm{a}_{\mathrm{wy}}$ & $\mathrm{a}_{\mathrm{wz}}$ & \\
\hline \multicolumn{5}{|c|}{ Rise } \\
\hline Standard/armored & $78.57 \%$ & $91.67 \%$ & $2.38 \%$ & $10.5 \%$ \\
\hline \multicolumn{5}{|c|}{ Downhill } \\
\hline Standard/armored & $81.82 \%$ & $88.89 \%$ & $18.42 \%$ & $4.65 \%$ \\
\hline
\end{tabular}

vehicle along each axis. The Table 4 points out that there's a reduction of the aw values for armored vehicle. In particular, the highest percentage reduction is measured along $\mathrm{X}$ and $\mathrm{Y}$ axis. Consequently, also the estimated daily exposure computed for each direction results greater for the standard vehicle. In fact, the dose referred to armored vehicles decreases from a minimum value of $4.65 \%$ (downhill) to a max value of $10.52 \%$ (rise). Furthermore, on the 
standard vehicle were recorded greater instantaneous peak accelerations in the sagittal plane ( $\mathrm{x}$ and $\mathrm{y}$ directions) while the vertical axis results more solicited on the armored car. Finally, it is necessary to underline that the tests were realized in the same boundary conditions, driving on the identic pavement road.

\section{CONCLUSIONS}

The driver's exposure to vibration in vehicles for the urban use is significant and poses relevant health hazards. The European Union and the ISO 2631-1(1997) recommend the calculation of the daily action values for $\mathrm{A}(8)$ in order to prevent injuries for human health. The present study was carried out with a view to highlight the effects of installation of bulletproof armor on the chassis and the WBV exposure. The field tests were realized under the same boundary conditions, as described above. The two vehicles compared in this study have the same driver's seat and structure but different total weight. This work follows the recommendation by the ISO 2631-1(1997) for the purpose of computing the WBV exposure parameters. The results highlight that there were significant interaction effects between model vehicle and WBV exposure. In other words, it is shown clearly that the level vibration measures on the driver's seat were generally less on the armored vehicle respect to standard model but greater for the instantaneous peak along $\mathrm{Z}$ axis. One possible explanation for this variation could be due to the different interactions between seat and vehicle chassis. Sure enough, a special material for ballistic protection is mounted on the armored vehicle chassis and it has an absorption effect. In addition, the suspension systems are different and consequently change the signal source vibration. This modification generated attenuation of frequency-weighted RMS. accelerations values all over the frequency spectrum and thus WBV exposures reduction. However, following the current study, on the base of these data it can be concluded that the addition of bulletproof armor has determined a generalized reduction of professional dose in a range from $5 \%$ to $11 \%$. In spite of the limited number of samples, the results strongly encourage further research. In particular may be developed appropriate vibration control system through seat suspension or specific materials in order to eliminate the resultant vibrations that affect the seated operator within the dumping process or design specifications of vehicle suspension parameters.

\section{REFERENCES}

[1] Porter, J.M. \& Gyi, D.E., The prevalence of musculoskeletal troubles among car drivers. Occupational Medicine, 52(1), p. 4, 2002.

[2] Mechanical Vibration \& Shock: Evaluation of Human Exposure to Whole-body Vibration, Part 1, General Requirements: International Standard ISO 2631-1: 1997 (E). ISO. ISO, 1997.

[3] Palmer, K.T., Griffin, M.J., Bendall, H., Pannett, B. \& Coggon, D., Prevalence and pattern of occupational exposure to whole body vibration in Great Britain: findings from a national survey. Occupational and Environmental Medicine, 57(4), pp. 229236, 2000.

[4] Pope, M., Magnusson, M., Lundström, R., Hulshof, C., Verbeek, J. \& Bovenzi, M., Guidelines for whole-body vibration health surveillance. Journal of Sound and Vibration, 253(1), pp. 131-167, 2002.

[5] Zhao, X. \& Schindler, C., Evaluation of whole-body vibration exposure experienced by operators of a compact wheel loader according to \{ISO\} 2631-1:1997 and \{ISO \} 2631-5:2004. International Journal of Industrial Ergonomics, 44(6), pp. 840-850, 2014. 
[6] Okunribido, O.O., Shimbles, S.J., Magnusson, M. \& Pope, M., City bus driving and low back pain: A study of the exposures to posture demands, manual materials handling and whole-body vibration. Applied Ergonomics, 38(1), pp. 29-38, 2007.

[7] Velmurugan, P., Kumaraswamidhas, L.A. \& Sankaranarayanasamy, K., Whole body vibration analysis for drivers of suspended cabin tractor semitrailer. Experimental Techniques, 38(2), pp. 47-53, 2014.

[8] McKinnon, C.D., Callaghan, J.P. \& Dickerson, C.R., Field quantification of physical exposures of police officers in vehicle operation. International Journal of Occupational Safety and Ergonomics, 17(1), pp. 61-68, 2011.

[9] Donnelly, C.J., Callaghan, J.P. \& Durkin J.L., The effect of an active lumbar system on the seating comfort of officers in police fleet vehicles. International Journal of Occupational Safety and Ergonomics, 15(3), pp. 295-307, 2009.

[10] Matsumoto, Y. \& Griffin, M.J., Mathematical models for the apparent masses of standing subjects exposed to vertical whole-body vibration. Journal of Sound and Vibration, 260(3), pp. 431-451, 2003.

[11] Durkin, J.L., Harvey, A., Hughson, R.L. \& Callaghan, J.P., The effects of lumbar massage on muscle fatigue, muscle oxygenation, low back discomfort, and driver performance during prolonged driving. Ergonomics, 49(1), pp. 28-44, 2006.

[12] Boileau, P.É. \& Rakheja, S., Whole-body vertical biodynamic response characteristics of the seated vehicle driver: Measurement and model development. International Journal of Industrial Ergonomics, 22(6), pp. 449-472, 1998.

[13] Alfaro Degan, G., Lippiello, D. \& Pinzari, M., Whole body vibrations: experimental assessment of anthropometric differences on the effects of WBV exposure in quarry workers. WIT Transactions on The Built Environment, 151, pp. 61-72, 2015.

[14] Hinz, B., Seidel, H., Hofmann, J. \& Menzel, G., The significance of using anthropometric parameters and postures of European drivers as a database for finiteelement models when calculating spinal forces during whole-body vibration exposure. International Journal of Industrial Ergonomics, 38(9-10), pp. 816-843, 2008.

[15] Hohl, G.H., Military terrain vehicles. Journal of Terramechanics, 44(1), pp. 23-34, 2007.

[16] Alfaro Degan, G., Coltrinari, G., Lippiello, D. \& Pinzari, M., Risk assessment of the whole-body vibration exposure for drivers of armored vehicles: A case study. International Journal of Safety and Security Engineering, 6(1), pp. 53-62, 2016. 